\title{
Leveraging Whole Life Cycle Costs when Utilising Building Information Modelling Technologies
}

\author{
Barry McAuley \\ Technological University Dublin, barry.mcauley@tudublin.ie \\ Dernot Kehily \\ Technological University of Dublin, dermot.kehily@tudublin.ie
}

Follow this and additional works at: https://arrow.tudublin.ie/beschreccon

Part of the Environmental Design Commons

\section{Recommended Citation}

Kehily, D., McAuley, B. and Hore, A.V (2012) Leveraging Whole Life Cycle Costs when utilising Building Information Modelling Technologies, International Journal of 3-D Information Modeling, Vol 1, No 4, PP 40 - 49 doi:10.21427/se3a-3869

This Conference Paper is brought to you for free and open access by the School of Surveying and Construction Management at ARROW@TU Dublin. It has been accepted for inclusion in Conference papers by an authorized administrator of ARROW@TU Dublin. For more information, please contact arrow.admin@tudublin.ie, aisling.coyne@tudublin.ie,gerard.connolly@tudublin.ie.

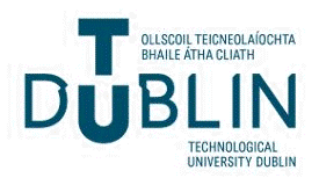




\title{
Leveraging Whole Life Cycle Costs When Utilising Building Information Modelling Technologies
}

Dermot Kehily, School of Real Estate and Economics, Dublin Institute of Technology, Dublin, Ireland

Barry McAuley, School of Real Estate and Economics, Dublin Institute of Technology, Dublin, Ireland

Alan Hore, School of Real Estate and Economics, Dublin Institute of Technology, Dublin, Ireland

\begin{abstract}
Building Information Modelling (BIM) is now being increasingly used as a technology tool to assist design professions in conceiving, designing, constructing, and operating the built environment in many countries. The BIM model provides design professions with the framework to perform exercises in design, programming, cost and value management, and concept energy analysis, in order to achieve the most economical and sustainable building solution. The BIM model though sophisticated is not extensively used to provide estimation software with the data requirements for Life Cycle Costing (LCC), such as, escalation of future expenditure and/or present value costs, discount rates, and study periods. Without incorporating LCC functionality within the BIM model or in an external application with a BIM interface a complete picture of the Whole Life Cycle Costs (WLCC) cannot be generated from the outputs of the model. The authors demonstrate the potential ability to customise traditional estimating packages with BIM take-off and database management interfaces, in order to find the best solution to provide complete Whole Life Cycle Costs Analysis (WLCCA). A template was produced in consultation with one of the internationally established methodologies in Life Cycle Costing (LCC) and provides the user with the financial tools to select the most economical advantageous solution, possibly without investing in new estimating software.
\end{abstract}

Keywords: $\quad$ Building Information Modelling (BIM), Estimating Software, Life Cycle Costs (LCC), Whole Life Cycle Costs (WLCC), Whole Life Cycle Cost Analysis (WLCCA)

DOI: $10.4018 / \mathrm{ij} 3 \operatorname{dim} .2012100105$ 


\section{INTRODUCTION}

Building Information Modelling (BIM) is beginning to change the way we build, the way buildings look, the way they function and the way buildings are maintained and managed (Godager, 2011). BIM has helped develop the way designers and contractors look at the entire building process, including the initial design brief, all the way through the construction documentation stage, into actual construction management stage, and finally the FM stage (Dzambazova et al., 2009). BIM can ensure a thorough life cycle analysis, service life planning and more solid life-cycle optimisations of the design and use of the buildings (Hallberg \& Tarnardi, 2011).

One of the key aspects of BIM is its ability to provide cost estimators with detailed $3 \mathrm{D}$ project views that combine vital information from tools within the BIM model. Quantity take-off and estimating using BIM software, in conjunction with cost data, is a comprehensive process that maps components of three-dimensional building models to material, labour and equipment cost data (Sylvester \& Dietrich, 2010). BIM offers the capability to generate take-offs, counts and measurements directly from a model, which provides a process where information stays consistent throughout the project and changes can be readily accommodated (Sabol, 2008). The BIM model, though sophisticated, is not extensively used to provide estimation software with the data requirements for Life Cycle Costing (LCC), such as escalation of future expenditure and/or Present Value (PV) costs, discount rates and study periods. Without incorporating LCC within the BIM model or in an external application with a BIM interface, a complete picture of the Whole Life Cycle Costs (WLCC) cannot be generated from the outputs of the model.

In order to successfully generate an accurate WLCC, it is recommended that a template, developed by the authors, be incorporated alongside BIM estimating software (with the ability to customise columns and add formulae) to provide a more detailed Whole Life Cycle
Costs Analysis (WLCCA). This will in turn provide the client with the financial tools required to select the most economical advantageous solution and eliminate the need for investing in new estimating software to carry out WLCCA.

\section{METHODOLOGY}

The authors have developed a template that can be incorporated into BIM estimating software (with column and function customisation) to provide more realistic WLCCA. This template was produced in consultation with a number of the internationally established methodologies in LCC. The template was created through an action research methodology, as it combines theory and practice through change and reflection in an immediate problematic situation, within a mutually acceptable ethical framework. Action research is an iterative process involving researchers and practitioners acting together on a particular cycle of activities, including problem diagnosis, action intervention, and reflective learning (Avison et al., 1999). It is not the intent of this paper to review BIM estimating software. Rather, this paper presents a generic template that can be incorporated into applicable BIM estimating packages. The template is currently under review and validation and may undergo improvements as a result of feedback from respondents.

This paper will also review a number of internationally established methodologies in LCC, outline the limitations within BIM costing software and review the calculations used in carrying out LCC. The literature review carried out by the authors has aided and informed the development of the template.

\section{BACKGROUND}

The authors conducted a literature review of journal papers, professional publications and research articles with regard to WLCC. The literature review focused on the three main areas detailed, in order to present the key areas required for the design of the WLCCA template: 
1. The Difference between WLCC and LCC within the BIM Interface;

2. WLCC Guidance Notes and Standard Method of Measurement in LCC;

3. Limitations within existing BIMEstimating tools.

\subsection{The Difference between WLCC and LCC within the BIM Interface}

LCC deals with assessing the total life costs of a component or asset throughout the construction, operation and disposal periods of the built assets life. However, it is the purpose of this paper to examine a WLCC approach towards BIM, which considers the wider commercial and economic implications of the asset to the client's organisation and end users. This, therefore, will enable a systematic economic consideration of all agreed significant costs and benefits associated with the acquisition and ownership of a constructed asset, which are anticipated over a period of analysis expressed in monetary value (BSI, 2008). The difference between both methods of analysis is explained in Figure 1.

In order for the authors to create a WLCCA template it is imperative to examine available guidance notes on WLCC and methods of measurement both nationally and internation- ally, so as to frame the work breakdown structure of the template within the most beneficial and applicable methodology.

\subsection{WLCC Guidance Notes and Standard Method of Measurement in LCC}

\subsubsection{SCSI: Guidance Notes on Life Cycle Costing}

The first process in the development of the WLCCA template was to conduct a review of Ireland's national guidance notes on LCC. The Society of Chartered Surveyors Ireland (SCSI) working group on LCC provides practical guidance and assistance for the society's members and quantity surveyors in Ireland, in carrying out LCCA and producing Life Cycle Cost Modelling (LCCM) in line with Ireland's Capital Works Management Framework (CWMF) (Kehily, 2011). The SCSI guidance notes are divided into six sections. Section 1 outlines a number of definitions for LCC and WLCC from internationally established methodologies and standard method of measurements in LCC. The section also discusses the applicability of WLCC in sustainable construction, risk management and tendering. Section 2 outlines and describes the data required in calculating PV factors, while Section 3 outlines the different

Figure 1. Difference between LCC and WLCC (BSI, 2008)

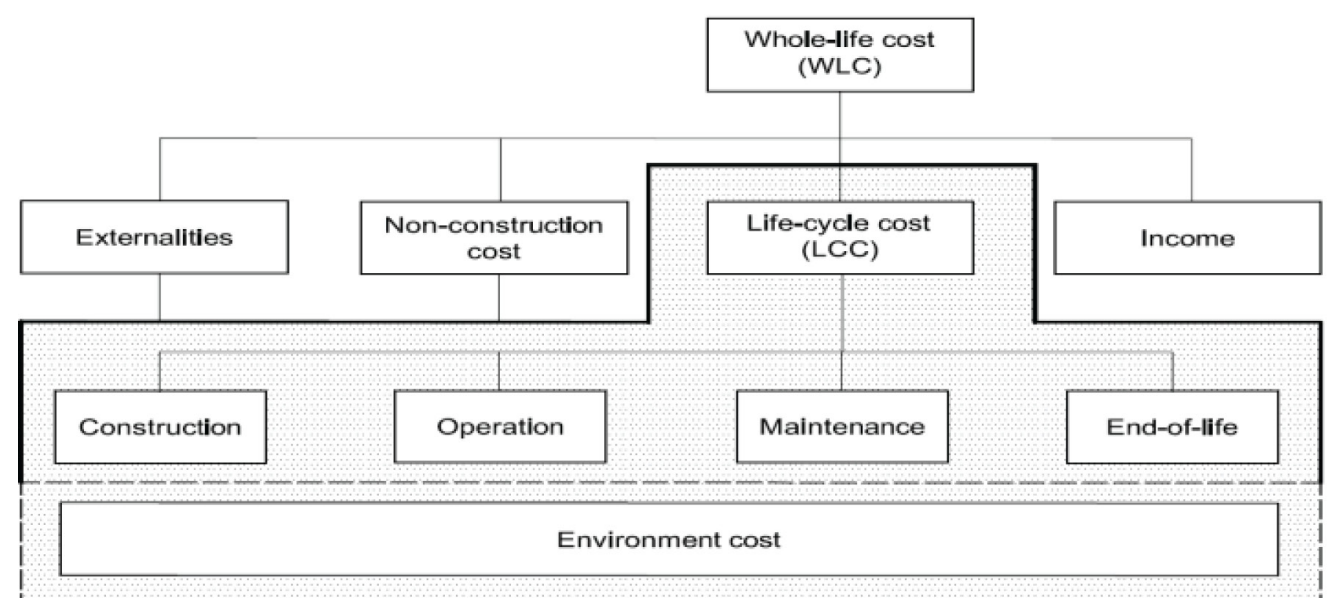


PV formulae used and when they may be used in LCC calculations. Section 3 outlines how a scientific calculator can be used to carry out PV calculations, but this method can be quite time consuming, as each variable must be inputted to determine the relevant factor (Fu et al., 2007). The LCC calculation must be repeated for each building component or system to determine the cumulative WLCC (Charette, 2010). Section 4 of the guidance notes describes how financial tables may be used to quickly calculate the relevant PV factors, outlining an example calculation for each of the PV factors, Single Present Value (SPV), Uniform Present Value (UPV), Single Present Value Modified (SPV*) and Uniform Present Value Modified (UPV*) (the symbol ' $*$ ' represents the modified version of the formulae - which includes escalation). Section 5 of the guidance notes demonstrates how PV factors can be written as formulae into excel cells. Once the data requirements and cost information are inputted into the template they are automatically calculated. Using this information cost professionals can build their own template and/or manipulate the template recommended by the working group. Section 6 of the guidance notes provides a fully worked example of an option appraisal of a building system over a given study period (Charette, 2010). Section 7 of the guidance notes reviews the most prevalent LCC standards and methodologies, a review of which is also addressed in Sections 3.2.2 and 3.2.3.

\subsubsection{Standard Method of Measurements for Life Cycle Costing}

There are a number of internationally established methodologies and standard method of measurements on WLCC. In The United States, the National Institute of Standards and Technology (NIST) published handbook 135 (Fuller \& Peterson, 1995), thirteen years before a similar standard methodology from the International Standard Organisation (ISO). 'NIST handbook 135 ' outlines in detail the LLC method "defining the criteria used and describing the assumptions and procedures to follow in performing evaluations and gives examples on to how to carry out LCC calculations" (Fuller \& Peterson, 1995). The handbook, however, does not give a work breakdown structure for preparing LCC estimates. In 2007, Davis Langdon published a report on the contribution of LCC to sustainable construction (Davis Langdon Management Consulting, 2007); the report provides an account of a research and development project to develop a common European methodology for LCC for sustainable construction within the European Union. Kelly and Hunter (2009) published a Royal Institution of Chartered Surveyors (RICS) research paper which also considers LCC as an economic evaluation of sustainable construction. The Office of Government Commerce (OGC) in the UK provides, as part of their suite in 'Achieving Excellence in Construction Procurement Guides,' a guide for WLCC and cost management (OGC, 2003), the guide outlines the principles of WLCC and describes a process made up of a framework for cost management and WLCC.

\subsubsection{BSI/BCIS Standardized Method of LCC, a Supplement to BS EN ISO 15686-5}

British Standards Institute (BSI) Standardised Method of Measurement for Life Cycle Costing, ISO, BS ISO 15686-5' (2008) "is a multipart series of international standards giving guidance on various aspects of planning the service life of buildings and constructed assets." Part 5 of the series "provides guidelines, definitions, principles and informative text on the application of LCC techniques in the context of service-life planning." The BSI and the British Cost Information Service (BCIS) in the UK jointly published a document which interpreted the BSI ISO document and put forward a more detailed standardised method for producing LCC (2008) applicable to the Irish/UK construction industry and to the key stages of the procurement process. The document provides a cost data structure and a method of measurement for LCC which aligns with and is based on the BSI ISO 15685-5. Figure 1 represents 
the cost breakdown structure applicable to the BSI, ISO document and BSI/BCIS supplement documentation. Figure 1 indicates that WLCC are broken up into four classification categories, non-construction costs, life cycle costs, income and externalities. Life cycle costs are in turn broken up into a number of sub-categories construction, maintenance, operation, occupancy and end of life costs.

With a review of suitable methodologies for the drafting of the WLCCA template now established, the next area of research in which the authors will now concentrate on, is how this template can address limitations within existing BIM Estimating tools.

\subsection{Limitations within Existing BIM Estimating Tools}

BIM tools have addressed the significant limitations of 2D drawings that lack the rich three-dimensional (3D) context which estimators need, in order to identify important cost-sensitive design features (Shen \& Issa, 2010) and have further helped estimators visualise real world conditions through a virtual three-dimensional construction of the building (Sylvester \& Dietrich, 2010). BIM has the potential to allow construction companies to estimate the cost of a project with more detail and accuracy, while reducing time and expenses needed (Sattineni $\&$ Bradford, 2011). The same authors further explain that since BIM recognises actual materials used in construction, the BIM has the potential to perform the quantity take-offs and through a database management interface, price BIM components necessary for cost estimating.

Although most BIM estimating applications have well developed take-off and pricing functions, in respect to construction costs, there are significant limitations within current BIM estimating tools that restrict the estimator gaining a WLCC perspective. One of the major limitations, as explained by Shen et al. (2007), is that the current IFC model is not semantically rich enough to cover all the construction process data and job conditions. This fact coupled with the realisation, as de- tailed by Sylvester and Dietrich (2010), that it may require several software packages to create viable and usable results, show, despite its complexity there are restrictions in interacting within the BIM interface to produce a WLCCA within the actual virgin model. An alternative to the predefined-data-model approach is to allow estimators to apply their own domainspecific judgments to the design features with the assistance of $3 \mathrm{D}$ visualisation and quantity data from BIM models (Shen \& Issa, 2010). Already many quantity surveying and estimating software applications, such as, CostOs, CostX, and Buildsoft have added a BIM interface to their existing applications, providing users with the ability to generate quantities from the imported 3D model. Some of these applications also provide users with the ability to add columns and functions to the default workbooks and settings. In these applications users can customise cost data to include adjustments for escalation and PV calculations. The authors have created a spreadsheet template which allows cost professionals to add their own domainspecific judgments through the customisation of traditional estimating packages with a BIM and cost database interface, in order to complete a WLCCA. The application of the template is explained in greater detail in the next section.

\section{CUSTOMISATION OF EXISTING BIM ESTIMATING SOFTWARE}

\subsection{Calculating the LCC Factors in Spreadsheet Cells}

LCC relies on predicting when elements of the building and its services will deteriorate to a condition where intervention is needed, and what the discounted cost of each intervention will be. LCC calculations, therefore, depend on numerous assumptions, all subject to a degree of uncertainty. When calculating LCC it is necessary to discount all future intervention costs to a comparable time base (Kehily, 2011). All future expenditure should be discounted with PV formulae to a cumulative sum in today's 
monetary value (Fuller \& Peterson, 1995). These calculations incorporate escalation and discount rates to account for different operations taking place at different times throughout the built asset's life cycle. This provides the cost consultant with an opportunity to evaluate different systems, solutions and building options over a selected study period (Ashworth, 1996; Kirkham, 2005; Kelly \& Hunter, 2009).

There are two types of LCC calculations required for costs, which occur on a regular basis, such as, routine maintenance and operations costs and those which are one-off costs, such as, major replacement. LCC calculations are described as UPV (uniform - at regular intervals) and SPV (single - one off future payment), respectively. Financial tables allow for PV calculations to be performed without the use of calculators. Most financial tables cover a wide range of discount rates, escalation rates and time periods. Financial tables are available for UPV and SPV calculations and these can either be modified or unmodified (where modified tables take price escalation into account in conjunction with the discount
rate)(Kehily, 2011). Alternatively, and arguably the fastest way to carry out PV calculations is to incorporate the formulae into a spreadsheet. PV calculations can be written into a formula in a spreadsheet cell and once completed the formula can be copied and pasted as required throughout the spreadsheet for each line item in the estimate. Figure 2 represents an extract from the 'Guide to LCC' from the SCSI (Kehily, 2011), indicating how the data requirements for both SPV* and UPV* factors, such as, escalation, discount rates and study periods can be calculated in spreadsheet cells.

\subsection{Formulation of the Template - Column Customisation}

The authors have produced a template to aid construction professionals producing LCCM's under the methodologies outlined and the calculations demonstrated in Figure 2. This template provides a suggested column layout in spreadsheet form to be imported into estimating software through the software's column customisation function. Once one row is imported it

Figure 2. Excel calculations in guide to LCC SCSI

SPV* Single Present Value Modified in Excel

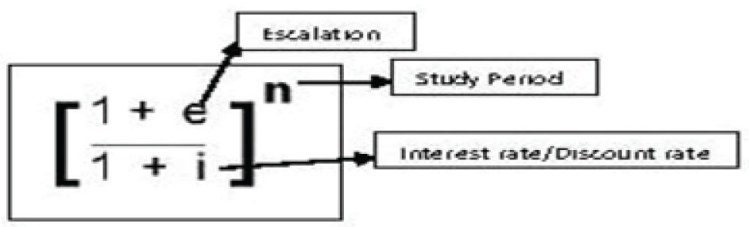

The S PV; formula shown above could be written into an excel cell as follows;

$=((1+e) /(1+i))^{\wedge} n$

UPV* Uniform PresentValue Modified in Excel.

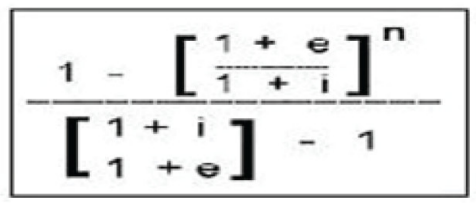

The UPV* formula above could be written into an excel cell as follows;

$\left.=\left(1-((1+e)(1+i))^{\wedge} n\right)((1+i)(1+e))-1\right)$ 
can be copied throughout the estimate or Bill of Quantities (BOQ) to provide LCC calculations to each line item in the estimate.

\subsubsection{How the Spreadsheet Works}

Figure 3 provides an example of the input involved in two rows of the spreadsheet. One row includes a calculation for a payment that occurs on a uniform basis (yearly or monthly) (UPV) and the second row outlines the calculations required for payments that occur at intervals throughout the evaluation period (SPV). The authors have demonstrated this example in a spreadsheet, as many BIM estimating applications simulate typical spreadsheet form in their workbooks. If the process can be carried out in a spreadsheet application it can be easily transferred to the software through the customisation function, alternatively the primary quantity and cost data generated in the software or the virgin BIM can be exported to the LCC spreadsheet template to generate a LCCM.

The first number of columns outlined in Figure 3 represents the typical data included in a cost plan or a BOQ; reference number (code); item description; quantity; unit; rate and total cost. The majority of these items can be copied or imported from the itemised cost plan and represent all those items that will be replaced within the total life (years) of the building. There is $2000 \mathrm{~m} 2$ of painting included in the example at a rate of $€ 8.50 / \mathrm{m} 2$. A 'factor' can be applied to the 'total cost' of painting to provide for any preparatory work (sanding, sealing) on the existing painting surface. The majority of cost plan items will need a factor applied to them for preparation, demolition and making good to receive new work over the original cost. Accounting for future costs are difficult to estimate given the variables that exist between the date of the estimate and the date the cost is incurred, the easiest way of calculating future expenditure of a cost plan item is to apply 'escalation' and 'discount' rates to the current 'factored cost,' over the selected time frame to calculate nominal 'escalated LCC costs,' and the 'present value' of the item.

The subsequent column to the factored costs provides a drop down selection for either UPV or SPV calculations. In the case of painting which occurs at certain intervals within the study period the relevant factor is a SPV. The following two columns represent the number of times painting will occur within the study period (intervals) and the years between each interval. The next two columns represent the total current 'LCC' (todays cost - without escalation and discount) and an annual cost representation of the total LCC. 'Escalation' (e) and

Figure 3. Extract from LCC template

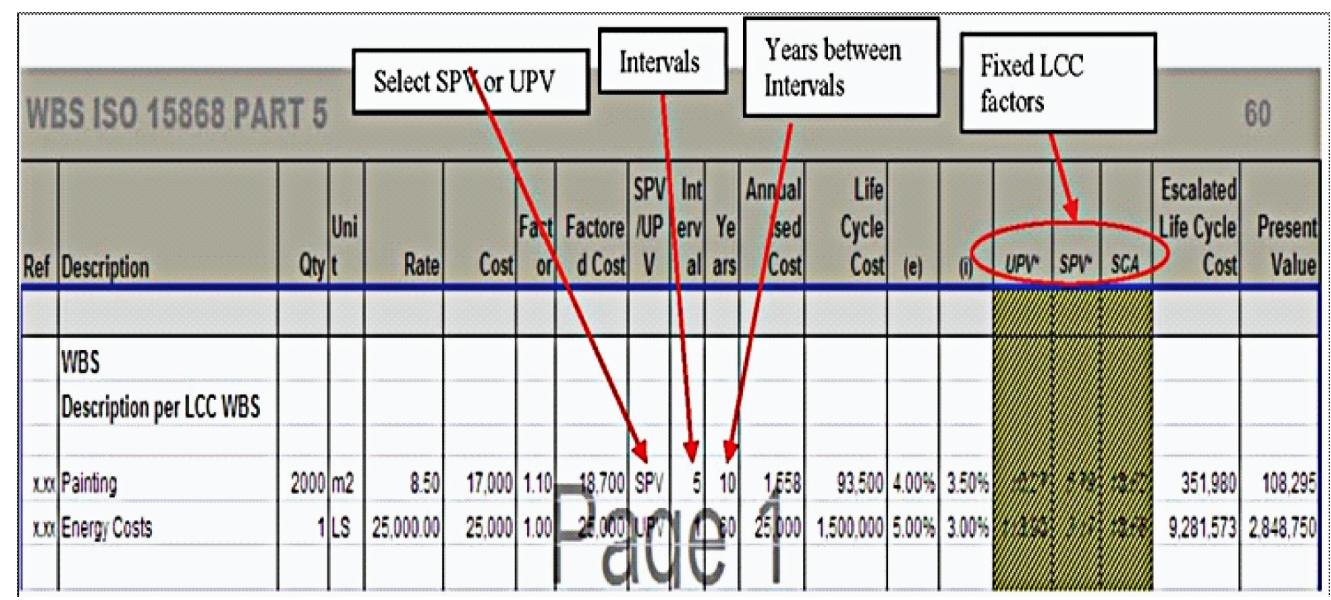

Copyright (C) 2012, IGI Global. Copying or distributing in print or electronic forms without written permission of IGI Global is prohibited. 
'discount' (i) columns are included to provide the rate variables for the succeeding 'escalated LCC' and 'PV' calculations. The PV factors and escalated factors are formulated within the columns for UPV*, SPV* and SCA. These calculations are fixed (thus they are highlighted out) and include the functions, which extract the variables from the relevant preceding cells to include them in the subsequent calculations. If any of the variables are changed the result would proliferate through the estimate without the need to reformulate the factors.

The 'Energy Costs' are one of the costs associated with the ISO15868-5 classification category, 'operations costs.' Changing variables in this sheet, through the inherent linkages will have an effect on 'the escalated LCC' and 'PV' calculations, as can be seen from the change in escalation rates from 5\% in Figure 3 to $7 \%$ in Figure 4. Energy costs differ from painting; for example, they are costs that recur on a uniform basis (UPV) rather than at certain intervals. For uniform costs the user will select 'UPV' from the drop down menu in the relevant column. Each row has the same inherent calculations but selecting either UPV or SPV will determine the factors to be applied and calculated to the variables in the subsequent columns. The variables are inputted similar to the painting example with the exception of the 'years' column which will include the total number of payments (years), in this case 60 no.

\subsection{Completing the Estimate}

The ISO, 'BS ISO 15686-5' (2008) and the 'NIST handbook 135' (Fuller \& Petersen, 1995) provides a coded Work Breakdown Structure (WBS) for carrying out LCC. The classification categories in the WBS provide a framework for presenting the LCC estimate and preparing costs. It is important to note that without the implementation of a standard WBS or methodology for LCC the process would live up to its documented failings of not following a standard approach (Cole \& Sterner, 2000). Incorporating the authors spreadsheet within the 4D BIM process also addressees some of the other documented barriers to successful implementation of LCC in practice. Some of these barriers as set out by Fu et al. (2007) in which the spreadsheet significantly reduces are:

\section{Lack of LCC data and a tool to manage} this data: The spreadsheet in conjunction with BIM estimating software can ensure that most LCC data can be accounted for and easily managed.

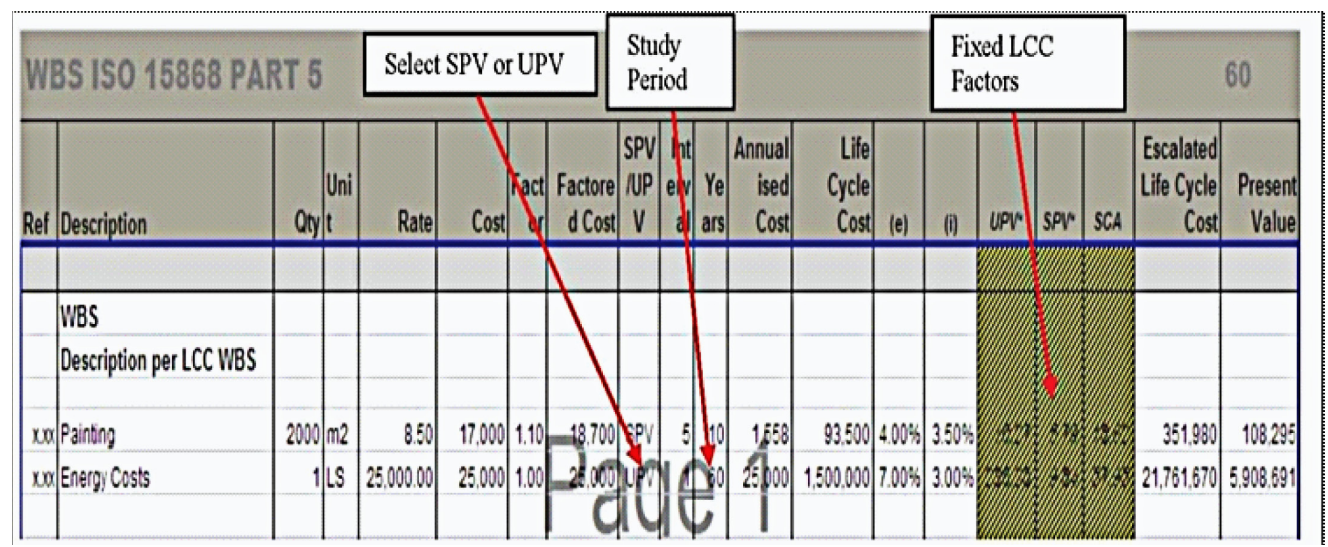


2. The complexity of calculations as a contributing factor: The spreadsheet has set formulae which can be easily transferred into a number of software packages.

3. Lack of in-house databases and sheer quantity of information that needs to be compiled: The estimating software has the ability to manage LCC data within its existing database and also has the capability to access external third party databases.

\section{CONCLUSION}

There are at present many estimating packages that now provide the user with the ability to generate quantities from the BIM and cost those quantities through a database tool within the application. Bringing the "complex" (Fu et al., 2007) LCC calculations into estimating software provides the user with the tools to generate the quantities, cost them and calculate the LCC in escalated costs and PV costs. This BIM model though sophisticated can find itself restricted and cannot provide estimation software with the data requirements for Life Cycle Costing (LCC) and without an external application cannot produce a complete WLCCA. The authors have demonstrated a generic template that can be incorporated within the 4D BIM process to address some of the documented barriers to successful implementation of LCC in practice. This template through a series of column and function customisations can help provide the estimator with a greater level of construction process data and job conditions without requiring numerous software packages to create viable and usable results.

\section{RECOMMENDATIONS}

Following one of the standard methodologies in LCC will provide the coded breakdown classification structure for the estimate. Although a very informative document, the NIST handbook from the US Department of Commerce (Fuller \& Peterson, 1995) fails to outline an applicable WBS. The authors recommend the use of the
ISO, 'BS ISO 15686-5' (2008) in conjunction with the supplement from the BSI/BCIS (2008) to provide a detailed classification structure to frame a WLCC with the authors template. The 'Guide to LCC' from the SCSI (Kehily, 2011) also provides valuable information in respect to understanding the calculations and relationship between the variables. It is recommended that cost consultants carrying out thorough WLCCA import the author's template into their existing software. This will in turn provide the client with the financial tools required to select the most economical advantageous solution and eliminate the need for investing in new estimating software to carry out WLCCA. The key benefits to cost professionals are; the ability to complete an WLLC exercise without having to do any of the time consuming PV calculations within their existing software; using the BIM interface to generate quantities and internal or external databases to cost them.

\section{REFERENCES}

Ashworth, A. (1996). Estimating the life expectancy of building components in life-cycle costing calculations. Structural Survey, 14(2), 4-8. doi:10.1108/02630809610122730

Avison, D., Lau, F., Myers, M., \& Nielsen, P. A. (2009). Action research: Make academic research relevant, researchers should try out their theories with practitioners in real situations and real organizations. Communications of the ACM, 42(1), 94-97. doi:10.1145/291469.291479

British Standard Institute (BSI). (2008). BS EN ISO 15686 Building and constructed asset - service life planning; Part 5 - Life cycle costing. London, UK: BSI.

British Standard Institute/British Cost Information Service (BSI/BCIS). (2008). Standardized method of life cycle costing for construction procurement, A supplement to BS EN ISO 15686-5 Building and constructed asset - Service life planning; Part 5 Life cycle costing. London, UK: BSI/BCIS.

Charette, R. (2010, May 15). Life cycle costing seminar/workshop for green buildings. Notes presented at the Workshop Session on Life Cycle Costing Seminar/ Workshop for Green Buildings, Dublin, Ireland. 
Cole, R., \& Sterner, E. (2000). Reconciling theory and practice of life cycle costing. Building Research and Information, 28(5-6), 358-375. doi:10.1080/096132100418519

Davis Langdon Management Consulting. (2007). Life cycle costing as a contribution to sustainable design: A common methodology. Retrieved September 3, 2010, from http://ec.europa.eu/enterprise/sectors/ construction/files/compet/life_cycle_costing

Dzambazova, T., Krygiel, E., \& Demchak, G. (2009). Introducing Revit ${ }^{\circledR}$ Architecture 2010: BIM for beginners. New York, NY: Sybex.

Fu, C., Kaya, S., Kagioglou, M., \& Aouad, G. (2007). The development of an IFC-based lifecycle costing prototype tool for building construction maintenance. Construction Innovation, 7(1), 85-58. doi:10.1108/14714170710721313

Fuller, S., \& Peterson, S. (1995). Life cycle costing manual for the federal energy management program (NIST Handbook No. 135). Washington, DC: United States Department of Commerce.

Godager, B. (2011, May 19-20). Analysis of the information needs for existing buildings for integration in modern BIM-based building information management. In Proceedings of the 8th International Conference on Environmental Engineering, Vilnius, Lithuania.

Hallberg, D., \& Tarandi, V. (2011). On the use of open BIM and $4 \mathrm{~d}$ visualisation in a predictive life cycle management system for construction works. ITcon, 16, 445-466.

International Standard Organisation. (2008). BS EN 15868-5:2008 Building and constructed asset - Service life planning; Part 5 - Life cycle costing. London, UK: British Standard Institute.

Kehily, D. (2011). Guide to life cycle costing. Dublin: Society of Chartered Surveyors Ireland.
Kelly, J., \& Hunter, K. (2009). Life cycle costing sustainable design. London, UK: RICS Research.

Kirkham, R. (2005). Re-engineering the whole life cycle costing process. Construction Management and Economics, 23(1), 9-14. doi:10.1080/014461 90410001678765

Office of Government Commerce. (2003). Whole life cycle cost management, procurement guide no 7; achieving excellence in construction. London, UK: Author.

Sabol, L. (2008). Challenges in cost estimating with building information modelling, design + construction strategies- The power of process in the built environment. Retrieved March 29, 2012, from http://www.dcstrategies.net/files/2_sabol_cost_estimating.pdf

Sattineni, A., \& Bradford, R. H. (2011). Estimating with BIM: A survey of U.S. construction companies. In Proceedings of the 28th International Symposium on Automation and Robotics in Construction, Seoul, Korea (pp. 564-569).

Shen, Z., \& Issa, R. R. A. (2010). Quantitative evaluation of the BIM-assisted construction detailed cost estimates. Journal of Information Technology in Construction, 15, 234-257.

Shen, Z., Issa, R. R. A., \& Gu, L. (2007). Semantic 3D CAD and its applications in construction industry - An outlook of construction data visualization. In G. Qiu, C. Leung, X. Xue, \& R. Laurini (Eds.), Proceedings of the 9th International Conference on Advances in Visual Information Systems (LNCS 4781, pp. 461-467).

Sylvester, K., \& Dietrich, C. (2010, April 7-10). Evaluation of Building Information Modeling (BIM) estimating methods in construction education. In Proceedings of the 46th ASC Annual International Conference, Boston, MA. Retrieved March 29, 2012, from http://ascpro.ascweb.org/chair/paper/ CEUE221002010.pdf 